\title{
Influence of a 50bp Ins/Del polymorphism at promoter of the superoxide dismutase-1 on gene expression and risk of heroin dependency
}

\author{
Khyber Saify and Mostafa Saadat ${ }^{*}$
}

\begin{abstract}
Objective: Superoxide dismutase-1 (SOD1, OMIM: 147450) is one of the major antioxidant enzymes, which plays a vital role in clearance of reactive oxygen species. A genetic polymorphism of $50 \mathrm{bp}$ insertion/deletion (Ins/Del) in the promoter region of the SOD1 was reported. The aims of the present study are to evaluate the influence of this polymorphism on the SOD1 mRNA levels in human peripheral blood cells and its association with risk of heroin dependency.
\end{abstract}

Methods: The present study consisted of 47 healthy students of Shiraz University (south-west Iran) for investigating the association between the Ins/Del polymorphism on expression level of SOD1, also a total of 442 heroin dependent and 799 healthy controls were included in a case-control study investigating the association between the study polymorphism and risk of dependency to heroin. The quantitative SOD1 mRNA expression levels were investigated using quantitative real-time PCR.

Results: Statistical analysis revealed a significant difference between the study genotypes $(t=5.17 ; \mathrm{df}=45 ; P<0.001)$. The Del allele of the study polymorphism decreased approximately 33\% of the SOD1 mRNA levels of the gene in the heterozygote individuals. Statistical analysis indicating that in both genders, neither the Ins/Del nor the Del/Del genotypes was associated with the risk of heroin addiction.

Conclusions: The present study indicating that although the Ins/Del polymorphism of SOD1 is associated with the SOD1 expression levels, this polymorphism is not associated with the risk of dependency to heroin.

Keywords: mRNA level, Ins/Del, Polymorphism, SOD1

\section{Introduction}

Superoxide dismutase-1 (EC 1.15.1.1; SOD1, OMIM: 147450), a major cytoplasmic antioxidant enzyme is a copper- and zinc-containing enzyme. The SOD1 metabolizes of highly reactive and more dangerous superoxide radicals into less reactive molecular oxygen and hydrogen peroxide $\left(\mathrm{H}_{2} \mathrm{O}_{2}\right)$, thus providing a defense against oxygen toxicity [1]. It should be noted that the $\mathrm{H}_{2} \mathrm{O}_{2}$ is subsequently converted into water by catalase or glutathione peroxidase. Failure in the conversion processes or imbalance between the production of reactive oxygen

\footnotetext{
* Correspondence: saadat@shirazu.ac.ir; msaadat41@yahoo.com Department of Biology, College of Sciences, Shiraz University, Shiraz 71467-13565, Iran
}

species and the antioxidant enzymes, results in cell damage, which leads to several multifactorial complex traits such as cancers, psychiatry diseases, etc [2-5].

Several genetic polymorphisms in the SOD1 have been reported in human populations (http://www.ncbi.nlm.nih. gov/projects/SNP/snp_ref.cgi?geneId=6647). Previous studregion of $S O D 1$ (1684 bp upstream of the ATG start codon) [12]. This is called $50 \mathrm{bp}$ insertion/deletion (Ins/Del) polymorphism. It has been shown that the $50 \mathrm{bp}$-deleted region contains a number of transcription factor binding sites. Studies indicate that the SP1 binds to this region. To 
determine if the $50 \mathrm{bp}$ Ins/Del polymorphism affects the basal transcription activity of the $S O D 1$, an in vitro study was published [12]. Functional studies to assess the SOD1 promoter activity in several human cell lines transfected with luciferase constructs, demonstrated that the Del allele reduce the activity of the $S O D 1$ promoter activity by approximately $50 \%$ [12]. In a more recent study, the $50 \mathrm{bp}$ deletion was found to be associated with a reduction in SOD1 enzymatic activity in erythrocytes of control subjects suggesting a moderate reducing effect on SOD1 synthesis [13]. The effect of this polymorphism on the mRNA levels of the SOD1 was studied in the peripheral blood cells of 48 patients with sporadic amyotrophic lateral sclerosis (ALS) and no difference was found among the genotypes [14]. There is no in vivo study on relationship between the Ins/Del polymorphism and promoter activity of the $S O D 1$ in healthy subjects.

Opiates may cause oxidative stress in drug dependent persons $[15,16]$. It has been reported that morphine decreases the mRNA level of mu-opioid receptor via production of reactive oxygen species (ROS) in human neuroblastoma SH-SY5Y cells [17]. Oxidative stress is very important in brain, because oxidative stress has effects on the integrity of DNA as well as on the function of the N-type and/or L-Type $\mathrm{Ca}^{2+}$ channel [18]. On the other hands, it has been demonstrated that SOD1 was expressed in the various parts of brain, including motor and sensory cranial nerve nuclei, as well as diffusely through the brain in the neurons of the cortex, certain regions of the hippocampus, and amygdale [19]. Very recently the alterations of the SOD1 mRNA levels in SH-SY5Y human cells exposed to methadone and morphine were reported $[20,21]$.

Although the association between GSTs polymorphisms and susceptibility to drug dependency has been reported [22-26], there are no study investigating the association between the Ins/Del polymorphism of the SOD1 and risk of heroin dependence. The aims of the present study are to evaluate the influence of the Ins/Del polymorphism on the SOD1 mRNA levels in human normal peripheral blood cells and investigating the association between this genetic polymorphism and risk of heroin dependence.

\section{Methods}

\section{Subjects}

The present study consisted of 47 (18 females, 29 males) healthy students of Shiraz University (south-west Iran) between the ages of 20 and 35 years (mean \pm SD: $25.3 \pm$ 3.3). A detailed description of these subjects has been reported in our previous report [27]. Considering that Iranian population is a heterogeneous population [28-30], we selected the participants from Persian (Caucasians) Muslims living in Shiraz (Fars province, south-west Iran).
Informed consent was obtained from each volunteer before the study. This study was approved by the Shiraz University ethics committee.

Sample size calculation was undertaken using the QUANTO (http://biostats.usc.edu/software) software. In order to detect a real difference in mRNA levels between the genotypes of the Ins/Del polymorphism with a power of $0.90, \alpha=0.05, R_{\mathrm{g}}^{2}$ (marginal proportion of variance in the SOD1 mRNA levels explain by the $50 \mathrm{bp}$ Ins $/$ Del polymorphism) $=0.25,15 \%$ frequency of the minor allele (the Del allele), a minimum sample of 27 would be necessary. Therefore, the present study is more than sufficiently powered with an $N=47$ subjects to detect a large effect in mRNA levels between the different genotypes.

This report also consist a case-control study performed in Shiraz (southern Iran) performed on 442 heroin dependent subjects (400 males, 42 females) and 799 healthy controls (662 males, 137 females). A detailed description of these subjects has been reported in our previous report [31]. All patients were assessed using the Structured Clinical Interview based on Diagnostic and Statistical Manual of Mental Disorders, fourth edition (DSM-IV) criteria for heroine and opium dependence. Moreover, urine drug screens were obtained. All patients were interviewed by a senior psychiatrist. The patients were in methadone maintenance for treating heroin dependency and all of them reported heroine as their primary drug of choice. Control individuals were blood donors, who declared that they did not suffer from substance abuse. Using the QUANTO software, to detect a real difference in genotypic frequency with a power of $0.80, \alpha=0.05, \mathrm{OR}=1.50$, and $15 \%$ frequency of the Del allele; a minimum sample of 331 would be necessary. The present case-control study (with 1241 subjects) is more than sufficiently powered to detect a smallmedium effect in genotype frequency between cases and controls.

\section{Measurements}

Genotyping for the SOD1 Ins/Del polymorphism was carried out using PCR based method, as described previously [32]. Total RNA was isolated from peripheral blood cells by RNX-Plus kit (CinnaGene, Iran) following the manufacturer's instructions. RNA samples were used for cDNA synthesis using the PrimeScript RT regent Kit (Takara, Japan). Relative abundance of the SOD1 mRNA level was assessed using quantitative real-time PCR using a Rotor-gene 6000 real-time PCR system (Corbett Life Science) by SYBR Green Premix Ex Taq II Kit (Takara, Japan), as described previously [22]. The "TATA box-binding protein" (TBP, OMIM: 600075) was used as calibrator gene. The SYBR green I fluorescence intensity was acquired at the end of extension step of each cycle. 
Relative differences in gene expression were expressed using cycle threshold $(\mathrm{Ct})$ values. $\triangle \mathrm{Ct}$ means difference of $\mathrm{Ct}$ between TBP and SOD1. The SOD1 expression for each individual was determining using $2^{-\Delta \mathrm{Ct}}$ [33].

\section{Statistical analysis}

Goodness-of-fit $\chi^{2}$ test was used to verify whether the distribution of SOD1 genotypes was in accordance with the Hardy-Weinberg equilibrium. The SOD1 expression levels were expressed as mean \pm SE. To evaluate the possible influence of the $50 \mathrm{bp}$ Ins/Del polymorphism in promoter region of the SOD1 on the expression levels of the student $t$-test. In order to exclude the possible influence of age and gender of participants on the relationship between the SOD1 mRNA levels and the study polymorphism, multiple regression analysis were used. In multiple regression analysis the SOD1 polymorphism was included in as number of the Del allele (0 and 1 used for Ins/Ins and Ins/Del genotypes, respectively, gender was coded as 0 for females and 1 for males and age of participants (years) was used as a covariate.

The associations between the genotypes and the risk of heroine dependence were assessed by odds ratios (ORs) and 95\% confidence intervals (CIs). Adjusted ORs for age and gender of participants were also estimated using logistic regression analysis. The reference group consisted of individuals with the Ins/Ins genotype. Statistical analysis was performed using the Statistical Package for Social Sciences (SPSS Inc.,
Chicago, IL, USA; version 11.5). A probability of $P<0.05$ was considered statistically significant.

\section{Results}

Association between the Ins/Del polymorphism and SOD1 mRNA levels in healthy individuals

In our samples, 33 and 14 participants have the Ins/ Ins and Ins/Del genotypes, respectively. Genotypes in the study group were in accordance with the HardyWeinberg equilibrium $\left(\chi^{2}=1.43, \mathrm{df}=1, \quad P=0.230\right)$. Because of low prevalence of the Del allele, we did not find the Del/Del genotype in our sample. The frequency of the Ins/Ins genotype was similar between female (0.66) and male (0.72) participants $\left(\chi^{2}=0.17\right.$, $\mathrm{df}=1, P=0.675)$. The age of participants with the Ins/Ins (mean $=25.6, \mathrm{SD}=3.6$ years) and Ins $/$ Del genotypes (mean $=24.6, \mathrm{SD}=2.1$ years) was similar $(t=0.97, \mathrm{df}=45$, $P=0.333)$. Figure 1 show the SOD 1 mRNA levels in Ins/Ins and Ins/Del genotypes. Statistical analysis revealed that there was a significant difference between the Ins/Ins and Ins/Del genotypes for the expression levels of SOD1 $(t=5.17, \mathrm{df}=45, P<0.001)$. Significant difference between the $S O D 1$ genotypes for the mRNA level was observed in multiple regression analysis when age and gender of participants were included in the analysis, as covariates (Table 1). The present analysis indicated that the 50 bp deleted allele, down-regulates (approximately $33 \%)$ the expression levels of the SOD1 in the heterozygote individuals.

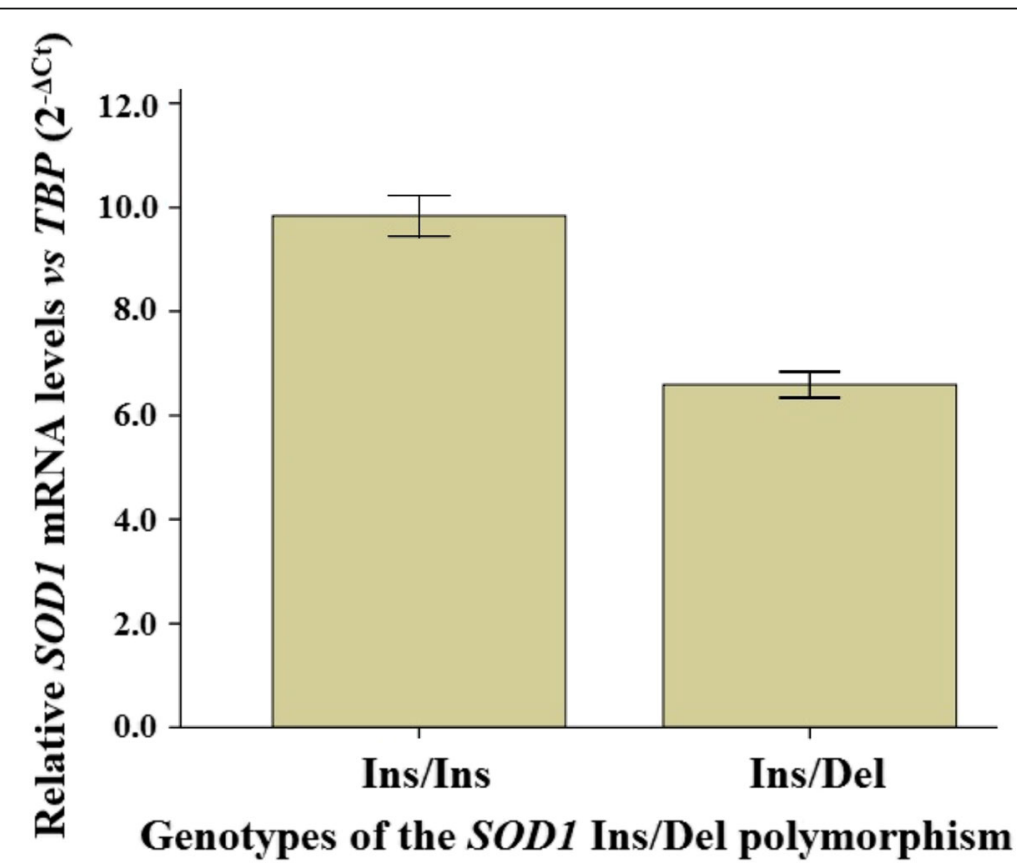

Fig. 1 The SOD 1 mRNA levels versus the TBP levels in the genotypes of the Ins/Del genetic polymorphism at promoter region of the SOD1 gene. Data were shown as mean $\pm \mathrm{SE}$ 
Table 1 Association between the mRNA levels of SOD1 and the $50 \mathrm{bp}$ Ins/Del genetic polymorphism at promoter region of the SOD1

\begin{tabular}{lllllll}
\hline Variables & \multicolumn{2}{l}{$\begin{array}{l}\text { Unstandardized } \\
\text { coefficients }\end{array}$} & $\begin{array}{l}\text { Standardized } \\
\text { coefficients }\end{array}$ & $\mathrm{t}$ & $P$ \\
\cline { 2 - 3 } & $\mathrm{B}$ & $\mathrm{SE}$ & Beta & & \\
\hline Constant & 11.563 & 2.408 & - & 4.801 & $<0.001$ \\
SOD1 polymorphism & & & & \\
Age & -3.340 & 0.640 & -0.629 & -5.217 & $<0.001$ \\
Gender $^{\mathrm{b}}$ & -0.051 & 0.090 & -0.069 & -0.567 & 0.573 \\
\hline
\end{tabular}

Adjusted $\mathrm{R}^{2}$ for model $=0.350 ; F=9.261 ; \mathrm{df}=3,43 ; P<0.001$

a $S O D 1$ polymorphism was included in analysis as number of the Del allele (0

and 1 used for Ins/Ins and Ins/Del genotypes, respectively)

${ }^{\mathrm{b}}$ Gender was coded as 0 for females and 1 for males

\section{Association between the Ins/Del polymorphism and dependence to heroine}

Table 2 shows the genotypic prevalence of the study polymorphism between the cases and healthy controls. The genotypic frequencies of the polymorphism in healthy controls $\left(\chi^{2}=1.63, \mathrm{df}=1, P=0.201\right)$ and patients $\left(\chi^{2}=1.38\right.$, $\mathrm{df}=1, P=0.239)$ were consistent with the Hardy-Weinberg equilibrium distribution. Considering the significant difference between genders for addiction risk and there are some reports on the significant differences between genders for the risks associated with drug dependency and genetic polymorphism [31], the analysis were performed on each gender group separately. Statistical analysis indicating that in both genders, neither the Ins/Del nor the Del/Del genotypes was associated with the risk of heroin addiction (Table 2). The same results were observed after ORs were adjusted for age and gender of participants (Table 2).

\section{Discussion}

The present study indicated that the Del allele, downregulates (approximately 33\%) the expression levels of the SOD1 in the heterozygote individuals, confirming the previous studies which they determined the expression levels of SOD1 in human cell lines transfected with luciferase constructs [12] and the study reporting that the $50 \mathrm{bp}$ deletion was found to be associated with a reduction in SOD1 enzymatic activity in erythrocytes of control subjects [13]. It should be noted that there is another study that published in 2012 by Milani and colleagues [14] that measured SOD1 mRNA levels in 48 ALS patients and they did not find a relevant difference. The inconsistency between our present finding and the finding of Milani and colleagues, at least in part might be interpreted by this point that we used healthy participants whereas they used ALS patients.

It has been shown that oxidative stress significantly associated with several multifactorial diseases [2-5]. On the other hands, based on the enzyme activity of SOD1 (converting highly toxic superoxide radicals into less reactive molecules, hydrogen peroxide and oxygen) [1] it is self-evident that this enzyme is potentially important in etiology of several complex diseases. Considering that the Del allele, leads to decreased of the activity of promoter of the SOD1; subsequently it may alter the level of ROS detoxification. Due to the high interaction of ROS with DNA, the Ins/Del genetic polymorphism may play an important role for inter-individual differences in maintaining the genome's integrity. Taken together, we hypothesis that this polymorphism can modulate the risk of dependency to heroine. However, the results of the

Table 2 Association between the $50 \mathrm{bp}$ Ins/Del genetic polymorphism at promoter region of the SOD1 and risk of heroin dependence

\begin{tabular}{|c|c|c|c|c|c|c|c|c|}
\hline \multirow[t]{2}{*}{ Genders/Genotypes } & \multirow[t]{2}{*}{ Controls N (\%) } & \multirow[t]{2}{*}{ Cases N (\%) } & \multicolumn{3}{|c|}{ Crud } & \multicolumn{3}{|c|}{ Adjusted } \\
\hline & & & $\mathrm{OR}$ & $95 \% \mathrm{Cl}$ & $P$ & $\mathrm{OR}$ & $95 \% \mathrm{Cl}$ & $P$ \\
\hline \multicolumn{9}{|l|}{ Both genders } \\
\hline Ins/Ins & $590(73.8)$ & $328(74.2)$ & 1.0 & - & - & $1.0^{\mathrm{a}}$ & - & - \\
\hline Ins/Del & $188(23.5)$ & $102(23.1)$ & 0.97 & $0.74-1.28$ & 0.863 & 0.96 & $0.73-1.28$ & 0.827 \\
\hline Del/ Del & $21(2.6)$ & $12(2.7)$ & 1.02 & $0.49-2.11$ & 0.941 & 1.01 & $0.49-2.09$ & 0.969 \\
\hline \multicolumn{9}{|l|}{ Males } \\
\hline Ins/Ins & $486(73.4)$ & $297(74.3)$ & 1.0 & - & - & $1.0^{\mathrm{b}}$ & - & - \\
\hline Ins/Del & $159(24.0)$ & $91(22.7)$ & 0.93 & $0.69-1.25$ & 0.663 & 0.94 & $0.70-1.26$ & 0.660 \\
\hline Del/ Del & $17(2.6)$ & $12(3.0)$ & 1.15 & $0.54-2.45$ & 0.707 & 1.16 & $0.55-2.46$ & 0.702 \\
\hline \multicolumn{9}{|l|}{ Females } \\
\hline Ins/Ins & $104(75.9)$ & $31(73.8)$ & 1.0 & - & - & $1.0^{\mathrm{b}}$ & - & - \\
\hline Ins/Del & $29(21.2)$ & $11(26.2)$ & 1.23 & $0.57-2.83$ & 0.556 & 1.27 & $0.57-2.83$ & 0.559 \\
\hline Del/ Del & $4(2.9)$ & $-(0.0)$ & - & - & - & - & - & - \\
\hline
\end{tabular}

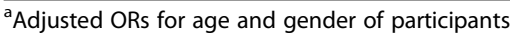

${ }^{\mathrm{b}}$ Adjusted ORs for age of participants 
present case-control study indicating that the risk of heroin dependence is not associated with the Ins/Del polymorphism of $S O D 1$; therefore our hypothesis was not confirmed.

It has been reported by epidemiological studies that high consumption of cruciferous vegetables would reduce cancer risk [34-36]. On the other hand, alteration in expression levels of SOD1 was reported when human hepatoma cell line (HepG2-C8) was exposed to some common phytochemicals present in cruciferous vegetables [37]. It should be noted that in the present study we did not ask the participants about their environmental factors and life style such as dietary consumption of cruciferous vegetables. Simultaneous study the influence of the SOD1 Ins/ Del polymorphism and environmental factors on the SOD1 mRNA level and risk of dependency to heroin should be further researched. Our present study has another limitation. We know that several polymorphisms were reported in SOD1 (http://www.ncbi. nlm.nih.gov/ projects/SNP/snp_ref.cgi? geneId $=6647$ ). The associations between some of these polymorphisms and several multifactorial traits were reported [6-11]. In the present study, however, we study only the $50 \mathrm{bp}$ Ins/Del in the promoter region of $S O D 1$.

\section{Acknowledgments}

The authors are indebted to the participants for their close cooperation. This study was supported by Shiraz University (Grant number 89GCU1M1741).

\section{Authors' contributions}

All authors contributed significantly to this work. KS contributed to experimental work and MS designed the experiments and analyzed the results. Both authors reviewed the manuscript and approved the final draft.

\section{Competing interests}

The authors declare that they have no competing interests.

\section{Publisher's Note}

Springer Nature remains neutral with regard to jurisdictional claims in published maps and institutional affiliations.

Received: 19 July 2016 Accepted: 4 March 2017

Published online: 15 March 2017

\section{References}

1. Niwa J, Yamada S, Ishigaki S, Sone J, Takahashi M, Katsuno M, Tanaka F, Doyu M, Sobue G. Disulfide bond mediates aggregation, toxicity, and ubiquitylation of familial amyotrophic lateral sclerosis-linked mutant SOD1. J Biol Chem. 2007;282:28087-95.

2. Smaga I, Niedzielska E, Gawlik M, Moniczewski A, Krzek J, Przegaliński E, Pera J, Filip M. Oxidative stress as an etiological factor and a potential treatment target of psychiatric disorders. Part 2. Depression, anxiety, schizophrenia and autism. Pharmacol Rep. 2015;67:569-80.

3. Che M, Wang R, Li X, Wang HY, Zheng XF. Expanding roles of superoxide dismutases in cell regulation and cancer. Drug Discov Today. 2016;21:143-9.

4. Beebe DC, Holekamp NM, Shui YB. Oxidative damage and the prevention of age-related cataracts. Ophthalmic Res. 2010;44:155-65.

5. He F, Zuo L. Redox Roles of Reactive oxygen species in cardiovascular diseases. Int J Mol Sci. 2015;16:27770-80.

6. Kim SH, Kim SH, Lee JH, Lee BH, Yoon HJ, Shin DH, Park SS, Jang SB, Park JS, Jee YK. Superoxide dismutase gene (SOD1, SOD2, and SOD3) polymorphisms and anti-tuberculosis drug-induced hepatitis. Allergy, Asthma Immunol Res. 2015;7:88-91.
7. Spisak K, Klimkowicz-Mrowiec A, Pera J, Dziedzic T, Aleksandra G, Slowik A. rs2070424 of the SOD1 gene is associated with risk of Alzheimer's disease. Neurol Neurochir Pol. 2014;48:342-5.

8. Ebrahimpour S, Saadat I. Association of CAT C-262 T and SOD1 A251G single nucleotide polymorphisms susceptible to gastric cancer. Mol Biol Res Commun. 2014:3:223-9.

9. Neves AL, Mohammedi K, Emery N, Roussel R, Fumeron F, Marre M, Velho G. Allelic variations in superoxide dismutase-1 (SOD1) gene and renal and cardiovascular morbidity and mortality in type 2 diabetic subjects. Mol Genet Metabol. 2012;106:359-65.

10. Mohammedi K, Maimaitiming S, Emery N, Bellili-Muñoz N, Roussel R, Fumeron F, Hadjadj S, Marre M, Velho G. Allelic variations in superoxide dismutase-1 (SOD1) gene are associated with increased risk of diabetic nephropathy in type 1 diabetic subjects. Mol Genet Metabol. 2011;104:654-60.

11. Kase BA, Northrup H, Morrison AC, Davidson CM, Goiffon AM, Fletcher JM, Ostermaier KK, Tyerman GH, Au KS. Association of copper-zinc superoxide dismutase (SOD1) and manganese superoxide dismutase (SOD2) genes with nonsyndromic myelomeningocele. Birth Defects Res Part A Clin Mol Teratol. 2012:94:762-9.

12. Broom WJ, Greenway M, Sadri-Vakili G, Russ C, Auwarter KE, Glajch KE, Dupre N, Swingler RJ, Purcell S, Hayward C, Sapp PC, McKenna-Yasek D, Valdmanis PN, Bouchard JP, Meininger V, Hosler BA, Glass JD, Polack M, Rouleau GA, Cha JH, Hardiman O, Brown Jr RH. 50 bp deletion in the promoter for superoxide dismutase 1 (SOD1) reduces SOD1 expression in vitro and may correlate with increased age of onset of sporadic amyotrophic lateral sclerosis. Amyotroph Lateral Scler. 2008;9:229-37.

13. Ingre C, Wuolikainen A, Marklund SL, Birve A, Press R, Andersen PM. A 50 bp deletion in the SOD1 promoter lowers enzyme expression but is not associated with ALS in Sweden. Amyotroph Lateral Scler Frontotemporal Degener. 2016;22:1-6.

14. Milani P, Gagliardi S, Bongioanni P, Grieco GS, Dezza M, Bianchi M, Cova E, Ceroni M, Cereda C. Effect of the 50 bp deletion polymorphism in the SOD1 promoter on SOD1 mRNA levels in Italian ALS patients. J Neurol Sci. 2012; 313:75-8.

15. Ghazavi A, Mosayebi G, Solhi H, Rafiei M, Moazzeni SM. Serum markers of inflammation and oxidative stress in chronic opium (Taryak) smokers. Immunol Lett. 2013;153:22-6.

16. Soykut B, Eken A, Erdem O, Akay C, Aydın A, Çetin MK, Dilbaz N. Oxidative stress enzyme status and frequency of micronuclei in heroin addicts in Turkey. Toxicol Mech Methods. 2013;23:684-8.

17. Ma J, Yuan X, Qu H, Zhang J, Wang D, Sun X, Zheng Q. The role of reactive oxygen species in morphine addiction of SH-SY5Y cells. Life Sci. 2015;124:128-35.

18. Hool LC. Evidence for the regulation of L-type $\mathrm{Ca}^{2+}$ channels in the heart by reactive oxygen species: mechanism for mediating pathology. Clin Exp Pharmacol Physiol. 2008;35:229-34.

19. Pardo CA, Xu Z, Borchelt DR, Price DL, Sisodia SS, Cleveland DW. Superoxide dismutase is an abundant component in cell bodies, dendrites, and axons of motor neurons and in a subset of other neurons. Proc Nat Acad Sci USA. 1995:92:954-8.

20. Saify K, Saadat M. Expression patterns of antioxidant genes in human SH-SY5Y cells after treatment with methadone. Psychiatry Res. 2015;230:116-9.

21. Saify K, Saadat I, Saadat M. Down-regulation of antioxidant genes in human SH-SY5Y cells after treatment with morphine. Life Sci. 2016;144:26-9.

22. Nakatome M, Miyaji A, Mochizuki K, Kishi Y, Isobe I, Matoba R. Association between the GST genetic polymorphisms and methamphetamine abusers in the Japanese population. Leg Med (Tokyo). 2009;11:468-70.

23. Khalighinasab MR, Saify K, Saadat M. Association between GSTM1 and GSTT1 genetic polymorphisms and susceptibility to methamphetamine dependence. Mol Biol Res Commun. 2015:4:25-32.

24. Khalighinasab MR, Saify K, Saadat M. Association between null alleles of GSTM1 and GSTT1 and dependence to heroin and opium. Psychiatry Res. 2015;228:977-8

25. Saify K, Khalighinasab MR, Saadat M. No association between GSTM1 and GSTT1 genetic polymorphisms and susceptibility to opium sap dependence. Mol Biol Res Commun. 2016:5:59-64.

26. Koizumi H, Hashimoto K, Kumakiri C, Shimizu E, Sekine Y, Ozaki N, Inada T, Harano M, Komiyama T, Yamada M, Sora I, Ujike H, Takei N, lyo M. Association between the glutathione S-transferase M1 gene deletion and 
female methamphetamine abusers. Am J Med Genet B Neuropsychiatr Genet. 2004;126B:43-5.

27. Saify K, Saadat I, Saadat M. Influence of A-21T and C-262T genetic polymorphisms at the promoter region of the catalase (CAT) on gene expression. Environ Health Prev Med 2016;21:382-6. DOI: 10.1007/s12199016-0540-4

28. Rafiee L, Saadat I, Saadat M. Glutathione S-transferase genetic polymorphisms (GSTM1, GSTT1 and GSTO2) in three Iranian populations. Mol Biol Rep. 2010;37:155-8.

29. Saadat M. Distribution of ACE insertion/deletion (I/D) polymorphism in Iranian populations. Mol Biol Res Commun. 2015;4:63-6.

30. Fallahzadeh-Abarghooei L, Zahedi T, Mirabedi F, Saadat M. Alleleic prevalence of intron 3 insertion/deletion genetic polymorphism of DNA double-strand break repair gene XRCC4 in four Iranian populations. Egypt J Med Hum Genet. 2015;16:215-8.

31. Saify K, Saadat I, Saadat M. Association between VNTR polymorphism in promoter region of prodynorphin (PDYM) gene and heroin dependence. Psychiatry Res. 2014;219:690-2.

32. Eskandari-Nasab E, Kharazi-Nejad E, Nakhaee A, Afzali M, Tabatabaei SP, Tirgar-Fakheri K, Hashemi M. 50-bp Ins/Del polymorphism of SOD1 is associated with increased risk of cardiovascular disease. Acta Med Iran. 2014:52:591-5.

33. Schmittgen TD, Livak KJ. Analyzing real-time PCR data by the comparative $C_{T}$ method. Nat Protoc. 2008:3:1101-8.

34. Higdon JV, Delage B, Williams DE, Dashwood RH. Cruciferous vegetables and human cancer risk: epidemiologic evidence and mechanistic basis. Pharmacol Res. 2007;55:224-36.

35. Chan R, Lok K, Woo J. Prostate cancer and vegetable consumption. Mol Nutr Food Res. 2009;53:201-16.

36. Tang L, Zirpoli GR, Guru K, Moysich KB, Zhang Y, Ambrosone CB, McCann $\mathrm{SE}$. Consumption of raw cruciferous vegetables is inversely associated with bladder cancer risk. Cancer Epidemiol Biomarkers Prev. 2008;17:938-44.

37. Saw $C L$, Cintrón $M, W u T Y$, Guo $Y$, Huang $Y$, Jeong $W S$, Kong AN. Pharmacodynamics of dietary phytochemical indoles $\mathrm{ISC}$ and DIM: Induction of Nrf2-mediated phase II drug metabolizing and antioxidant genes and synergism with isothiocyanates. Biopharm Drug Dispos. 2011;32:289-300.

\section{Submit your next manuscript to BioMed Central and we will help you at every step:}

- We accept pre-submission inquiries

- Our selector tool helps you to find the most relevant journal

- We provide round the clock customer support

- Convenient online submission

- Thorough peer review

- Inclusion in PubMed and all major indexing services

- Maximum visibility for your research

Submit your manuscript at www.biomedcentral.com/submit 